\title{
Acquisition of Sequences Homologous to Host DNA by Closed Circular Simian Virus 40 DNA
}

\author{
III. Host Sequences
}

\author{
SHMUEL ROZENBLATT, SARA LAVI, MAXINE F. SINGER, ${ }^{1}$ AND ERNEST WINOCOUR \\ Department of Genetics, Weizmann Institute of Science, Rehovot, Israel
}

Received for publication 1 March 1973

\begin{abstract}
A preparation of serially passaged simian virus 40 (SV40) DNA, in which at least $66 \%$ of the molecules contain covalently linked cellular DNA sequences, was digested to completion with the Hemophilus influenzae restriction endonuclease. Polyacrylamide gel electrophoresis of the digest showed that the majority of the cleavage products migrated as nine classes of fragments, each class defined by a particular molecular weight. These classes of fragments differ in molecular weight from the fragments produced by the action of the same enzyme on plaque-purified virus DNA. Three classes of fragments were present in less than equimolar amounts relative to the original DNA. The remaining six classes of fragments each contain more than one fragment per original DNA molecule. DNA-DNA hybridization analysis (using the filter method) of the isolated cleavage products demonstrated the presence of highly reiterated cell DNA sequences in two of the nine classes of fragments. A third class of fragments hybridized with high efficiency only to serially passaged SV40 DNA; the level of hybridization to plaque-purified virus DNA was low and there was essentially no hybridization with cell DNA immobilized on filters. It is suggested that this class of fragments contains unique host sequences. It was estimated that at least $27 \%$ of the sequences in the substituted SV40 DNA molecules studied are host sequences. The majority of these are probably of the nonreiterated type.
\end{abstract}

In the accompanying (6) and previous report (7), we showed that serial undiluted passage of several simian virus 40 (SV40) plaque isolates results in the accumulation of closed circular virus DNA molecules containing covalently linked host DNA sequences. These "substituted" virus DNA molecules replicate during serial undiluted passage even though they are defective with respect to plaque formation (6). In this paper, we report experiments on the structure of the substituted viral DNA produced in cells infected with one line of serially passaged virus. The data concern the proportion of host cell DNA sequences in the average substituted molecule and the types of host sequences found.

The analysis depends primarily on the use of the restriction endonuclease from Hemophilus influenzae (5, 10). Danna and Nathans (4) showed that this enzyme preparation makes 11 double-stranded breaks in DNA from plaquepurified SV40. The resulting 11 fragments can

'Permanent address: National Institute of Arthritis and Metabolic Diseases, National Institutes of Health, Bethesda, Md. 20014. be resolved according to size, by polyacrylamide gel electrophoresis. Nathans and Danna (9) also pointed out the potential usefulness of the restriction enzyme in studying alterations in SV40 DNA. We have indeed observed marked differences between the fragments obtained from DNA of plaque-purified SV40 and those obtained from DNA of serially passaged virus. These changes, and the characteristics of the fragments revealed by hybridization experiments, indicate that in the particular DNA studied, extensive portions of the SV40 genome are replaced by host sequences. Further, the data suggest that both reiterated and unique host sequences $(2,8)$ are present in the substituted SV40 DNA. Similar conclusions have been reached by $D$. Nathans and his colleagues in their study of serially passaged SV40 DNA (personal communication).

\section{MATERIALS AND METHODS}

Unless stated otherwise, the materials, the methods, and the abbreviations used in the text are as described in the accompanying paper (6). 
Virus. All the experiments reported here were carried out with the plaque-purified SV40 stock designated CVB, series 1 , and serially passaged derivatives of this stock (6).

Preparation of labeled SV40 DNA. Cultures of 4 $\times 10^{6}$ monkey BS-C-1 cells were infected with $1 \mathrm{ml}(2$ $\times 10^{8} \mathrm{PFU}$ ) of plaque-purified stock virus or with $1 \mathrm{ml}$ (1-2 $\times 10^{8}$ PFU) of serial undiluted passages 1,2 , and 3 . The infected cells were labeled, between 24 and $48 \mathrm{~h}$ after infection, with ${ }^{32} \mathrm{P}$ or ${ }^{3} \mathrm{H}-\mathrm{TdR}$, and SV40 component I DNA was isolated and purified by $\mathrm{CsCl}$ ethidium bromide equilibrium centrifugation as already described (6). After removal of the ethidium bromide from the pooled fractions containing component $\mathrm{I}$, the ${ }^{3} \mathrm{H}-\mathrm{SV} 40$ DNA molecules were precipitated with alcohol and redissolved in $0.1 \times \mathrm{SSC}$. The specific radioactivity of the ${ }^{3} \mathrm{H}-\mathrm{DNA}$ was about $1.5 \times$ $10^{5}$ counts per min per $\mu \mathrm{g}$.

Digestion of SV40 DNA with $H$. influenzae restriction endonuclease. The $H$. influenzae restriction endonuclease was generously supplied by Kathleen Danna and Daniel Nathans (4). It was stored at $-20 \mathrm{C}$, in $50 \%$ glycerol at a concentration of $6 \mathrm{U} / \mathrm{ml}$ (10). Reaction mixtures $(0.12 \mathrm{ml})$ contained $6.6 \mathrm{mM}$ Tris-hydrochloride $(\mathrm{pH} 7.4), 6.6 \mathrm{mM} \mathrm{MgCl}_{2}, 0.05 \mathrm{M}$ $\mathrm{NaCl}$, and 6. mM $\beta$-mercaptoethanol. The concentrations of DNA and enzyme are stated in the appropriate legends. After $2 \mathrm{~h}$ of incubation at $37 \mathrm{C}$, reactions were stopped by adding concentrated EDTA to a final concentration of $0.01 \mathrm{M}$. The completion of the enzyme reaction was monitored by diluting a small sample 50 -fold in $0.1 \times \mathrm{SSC}$ and sedimenting it through a 5 to $20 \%$ (wt/wt) sucrose gradient, prepared in $1 \times \mathrm{SSC}, 0.05 \mathrm{M}$ Tris-hydrochloride ( $\mathrm{pH} 7.9$ ) (Spinco SW50.1 rotor, $45,000 \mathrm{rpm}, 5 \mathrm{~h}$ at $4 \mathrm{C}$ ). Under these conditions, SV40 component I DNA sediments at $21 \mathrm{~S}$, and the mixture of fragments produced by digestion of component I with $H$. influenzae restriction endonuclease sediments as a peak from 7 to $9 S$ (4). The gel electrophoresis patterns of both the plaque-purified and serially passaged SV40 DNA digestion products did not change when either the reaction times or the enzyme-to-DNA ratios were increased, or when fresh enzyme was added during the course of the reaction.

Polyacrylamide gel electrophoresis. The products of degradation of SV40 by $H$. influenzae restriction enzyme were analyzed by electrophoresis on 0.6 -cm diameter $5 \%$ polyacrylamide gels, 12.9 to 13.1 $\mathrm{cm}$ in length, as described by Danna and Nathans (4). Electrophoresis was at $60 \mathrm{~V}$, for between 6 and $10.5 \mathrm{~h}$ at a room temperature of 21 to $22 \mathrm{C}$. After enzyme digestion, samples were treated in one of the following ways. (i) Direct application to gels: reaction mixtures were diluted with an equal volume of $20 \%$ (wt/wt) sucrose containing $2 \%$ sodium dodecyl sulfate, incubated for $15 \mathrm{~min}$ at $37 \mathrm{C}$, and 50 - to 200 - $\mu$ liter samples were loaded onto the gels. (ii) Application to gels after phenol extraction: the reaction mixture was diluted to $1 \mathrm{ml}$ with $0.01 \times \mathrm{SSC}$, shaken for $15 \mathrm{~min}$ with $1 \mathrm{ml}$ of $90 \%$ phenol, and centrifuged at low speed. The upper aqueous phase was made $0.3 \mathrm{M}$ in $\mathrm{NaCl}$, the DNA was precipitated with $2 \mathrm{vol}$ of alcohol, and the precipitate was collected by centrifugation for 30 min at $13,000 \mathrm{rpm}$. The DNA was dissolved in $0.1 \times$
SSC, diluted with an equal volume of $20 \%$ (wt/wt) sucrose containing $2 \%$ sodium dodecyl sulfate, incubated for $15 \mathrm{~min}$ at $37 \mathrm{C}$, and applied to the gel. (iii) Application to gels after sucrose gradient fractionation: a sample of the reaction mixture was sedimented through a neutral sucrose gradient, and the radioactive material in the 7 to $9 S$ region of the gradient was pooled, dialyzed against $0.1 \times \mathrm{SSC}$, precipitated from $0.3 \mathrm{M} \mathrm{NaCl}$ by 2 vol of ethanol, and redissolved in 0.1 $\times$ SSC. After dilution with sucrose-sodium dodecyl sulfate, as above, the sample was loaded onto the gels.

After electrophoresis the gels were frozen and sliced into 1 -mm slices. In analytical experiments, each slice was incubated in $0.3 \mathrm{ml}$ of $30 \% \mathrm{H}_{2} \mathrm{O}_{2}$ at $55 \mathrm{C}$ for 6 to 7 h (13) after which $0.7 \mathrm{ml}$ of $\mathrm{H}_{2} \mathrm{O}$ and $10 \mathrm{ml}$ of Triton $\mathrm{X}-100$ toluene scintillation fluid were added to each cooled vial.

For preparation of fragments, the ${ }^{3} \mathrm{H}-\mathrm{DNA}$ was eluted from the gel slices by incubating each slice for $48 \mathrm{~h}$ at $37 \mathrm{C}$ in $3 \mathrm{ml}$ of a solution containing $90 \mathrm{ml}$ of $100 \%$ formamide, $1 \mathrm{ml}$ of $1 \mathrm{M}$ Tris-hydrochloride $(\mathrm{pH}$ 6.7) and $9 \mathrm{ml}$ of $\mathrm{H}_{2} \mathrm{O}$ and made to a final $\mathrm{pH}$ of 9.1 . The vials were shaken at $200 \mathrm{rpm}$ during the elution period. Samples (generally $15 \mu$ liters) of each eluate were counted in Triton X-100-toluene scintillation fluid to obtain the fragment pattern, and selected fractions were pooled and centrifuged at low speed to remove insoluble material.

DNA-DNA hybridization. The method used was the same as described previously $(6,7)$ except that the radioactive DNA was denatured by incubation at $37 \mathrm{C}$ for 1 to $2 \mathrm{~h}$ in a solution containing 90 $\mathrm{ml}$ of $100 \%$ formamide, $1 \mathrm{ml}$ of $\mathrm{M}$ Tris-hydrochloride ( $\mathrm{pH} 6.7$ ), and $9 \mathrm{ml}$ of $\mathrm{H}_{2} \mathrm{O}$ adjusted to a final $\mathrm{pH}$ of 9.1 (this is the same solution used to elute fragments from gel slices and to elute hybridized DNA from the nitrocellulose membrane filters). The solutions were then adjusted to the concentrations of formamide, $\mathrm{NaCl}$, sodium dodecyl sulfate, and Trishydrochloride buffer, appropriate for hybridization (7) by the addition of $0.8 \mathrm{vol}$ of a solution containing $1.35 \mathrm{M} \mathrm{NaCl}, 0.9 \%$ sodium dodecyl sulfate, and 0.09 M Tris-hydrochloride ( $\mathrm{pH} 7.0)$ (the $\mathrm{pH}$ of the final solution is approximately 7.6). To determine the amount of radioactivity put into the hybridization reaction, after the formamide denaturation, $0.1-\mathrm{ml}$ samples of the final solutions were diluted with $0.9 \mathrm{ml}$ of $\mathrm{H}_{2} \mathrm{O}$ and counted in Triton X-toluene scintillation fluid. The efficiency of ${ }^{3} \mathrm{H}$ counting is the same as that obtained for aqueous samples dried onto membrane filters (Millipore Corp.) and counted in toluene-based scintillation fluid.

\section{RESULTS}

Proportion of SV40 DNA I molecules which contain host sequences. The substituted SV40 DNA molecules used for the studies with $H$. influenzae restriction endonuclease were produced by infecting BS-C-1 cells with serial, undiluted passages of a plaque-purified virus stock. To determine the proportion of substituted molecules synthesized at each passage level, full length (nonfragmented) virus DNA 
strands were tested for their ability to hybridize to BS-C-1 cell DNA immobilized on a filter. The results (Table 1) show a progressive increase in relative hybridization to host DNA with serial, undiluted passage. Relative hybridization is expressed by the ratio (6) of [ percent bound to BS-C-1 DNA)/(percent bound to plaque-purified SV40 DNA)] $\times 100$. After infection with passage 3 virus, at least $66 \%$ of the viral DNA molecules produced contain BS-C-1 sequences that register in the hybridization reaction. The high efficiency with which these DNA strands bind to BS-C-1 cell DNA indicates that at least a portion of the BS-C-1 sequences present in the substituted viral DNA molecules represent the reiterated cellular DNA sequences. The experiment does not exclude, of course, the possibility that a given substituted viral DNA chain may contain unique as well as reiterated DNA sequences.

Cleavage of plaque-purified and serially passaged SV40 DNA I molecules by the restriction endonuclease from $H$. influenzae. SV40 DNA I molecules from cells infected with plaque-purified virus and the three undiluted serial passages of the plaque-purified virus (Table 1) were digested to completion with the restriction endonuclease. The polyacrylamide gel electrophoresis pattern (Fig. 1) obtained with the progeny of the plaque-purified virus
(SV40 strain 777) is similar, if not identical, to the pattern published by Danna and Nathans (4) for small-plaque SV40, strain 776. There are nine distinct peaks of radioactivity. A plot (Fig. 1 , top) of percent radioactivity in each peak against slice number (electrophoretic mobility is proportional to chain length) gives a straight line if the percent of radioactivity in the third and fourth peaks from the origin is divided by two. Radioautography of a gel similar to that described in Fig. 1 has confirmed the finding (4) that the third and fourth peaks are doublets $(\mathrm{C}$ $+\mathrm{D}, \mathrm{E}+\mathrm{F}$ ), each containing two classes of fragments which differ slightly in their electrophoretic mobility. The straight line relationship shown in Fig. 1 (top) implies that every molecule of plaque-purified SV40 DNA generates one each of fragments A-K after cleavage with the endonuclease. The same results were obtained for SV40 DNA I molecules isolated from virions rather than from infected cells.

Changes from the cleavage pattern found with plaque-purified SV40 DNA are evident even after the first serial passage (Fig. 2B) when only $4.7 \%$ of the DNA molecules hybridize with BS-C-1 DNA (Table 1). A new class of fragments has appeared between the double peaks, $\mathrm{C}+\mathrm{D}$ and $\mathrm{E}+\mathrm{F}$, and a very small amount of a class of fragments with very high mobility (low molecular weight) has appeared at slice number

TABLE 1. Proportion of substituted SV40 DNA molecules synthesized in cells infected with serially passaged virus

\begin{tabular}{|c|c|c|c|c|}
\hline \multirow{3}{*}{$\begin{array}{l}\text { Infecting } \\
\text { virus }^{a}\end{array}$} & \multicolumn{4}{|c|}{ Hybridization of progeny ${ }^{3} \mathrm{H}-\mathrm{SV} 40 \mathrm{DNA}^{\circ}$} \\
\hline & \multirow{2}{*}{$\begin{array}{c}\text { Input } \\
\text { counts/min }\end{array}$} & \multicolumn{2}{|c|}{$\begin{array}{l}\% \text { of input bound to } \\
\text { filters containing: }\end{array}$} & \multirow{2}{*}{$\begin{array}{c}\text { Hybridization } \\
\text { index: } \\
\text { (BS-C-1/SV40) } \\
\quad \times 100\end{array}$} \\
\hline & & $\begin{array}{l}\text { SV40 } \\
\text { DNA }\end{array}$ & $\begin{array}{l}\text { BS-C-1 } \\
\text { DNA }\end{array}$ & \\
\hline $\begin{array}{l}\text { CVB, plaque-purified stock } \\
\text { CVB, passage } 1 \\
\text { CVB, passage } 2 \\
\text { CVB, passage } 3\end{array}$ & $\begin{array}{r}13,200 \\
15,120 \\
6,481 \\
9,563\end{array}$ & $\begin{array}{c}85 \\
64 \\
95 \\
125^{c}\end{array}$ & $\begin{array}{r}1 \\
3 \\
29 \\
83\end{array}$ & $\begin{array}{l}1.2 \\
4.7 \\
30 \\
66\end{array}$ \\
\hline
\end{tabular}

a These virus preparations are described in detail in Table 1 (CVB, series 1) and Table 2 of the accompanying paper (6).

${ }^{\circ} \mathrm{H}-\mathrm{SV} 40$ DNA (component I) from BS-C-1 cells infected with the virus preparations noted above was purified by $\mathrm{CsCl}$-ethidium bromide centrifugation. The ${ }^{3} \mathrm{H}-\mathrm{SV} 40 \mathrm{DNA}$ I was stored frozen at $-20 \mathrm{C}$ for about 1 week and then centrifuged through alkaline $\mathrm{CsCl}$ solutions (7). About 55 to $60 \%$ of component I had been converted to component II (presumably because of radiochemical damage during storage in the frozen state), and this component II was collected and used for hybridization, as described in Materials and Methods. To confirm that storage at $-20 \mathrm{C}$ produces component II DNA, a sample of the stored ${ }^{3} \mathrm{H}-\mathrm{SV} 40$ DNA (after alkaline $\mathrm{CsCl}$ centrifugation to remove residual component I) was mixed with ${ }^{14} \mathrm{C}-\mathrm{SV} 40 \mathrm{DNA}$ II (obtained by treating ${ }^{14} \mathrm{C}-\mathrm{SV} 40$ DNA I with diluted pancreatic DNase (12) and sedimented in a 5 to $20 \%$ alkaline sucrose gradient (SW41 rotor, $26,000 \mathrm{rpm}, 22 \mathrm{~h}, 21 \mathrm{C})$. The bulk $(90 \%)$ of the ${ }^{3} \mathrm{H}$-DNA cosedimented with ${ }^{14} \mathrm{C}$-component II DNA in 2 peaks, at $18 S$ and $16 S$, as expected for the single-stranded circular and single-stranded linear conversion products, respectively (12).

c The greater than $100 \%$ value is probably due to an inaccuracy in the determination of the input. However, the hybridization index of $66 \%$ is not affected by this error. 


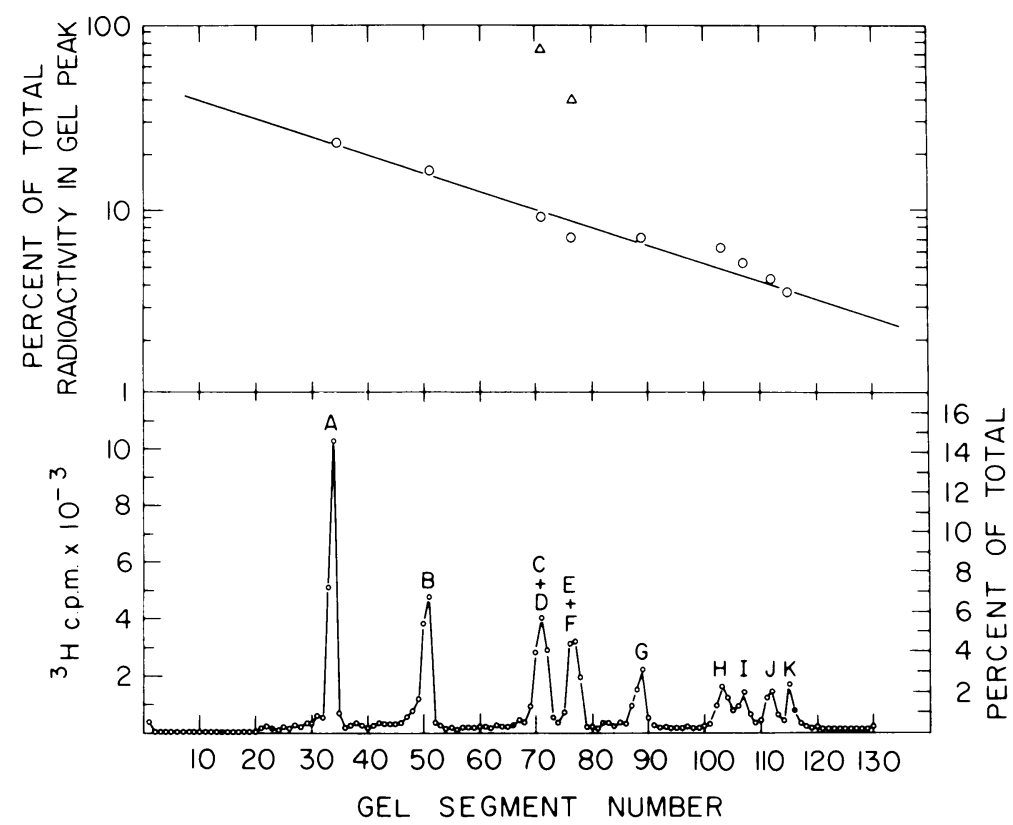

FIG. 1. Polyacrylamide gel electrophoresis of plaque-purified SV40 DNA (strain 777) digested with $H$. influenzae restriction endonuclease. ${ }^{3} \mathrm{H}-S V 40 \mathrm{DNA}$, component I, was isolated and purified from BS-C-I cells infected with plaque-purified CVB virus (see Table 1) as described in Materials and Methods. Digestion was with $0.11 \mathrm{U}$ of $\mathrm{H}$. influenzae endonuclease and $8 \mu \mathrm{g}$ of DNA per $\mathrm{ml}$. The reaction products were applied directly to the gel (see Materials and Methods), and electrophoresis was for $10.5 \mathrm{~h}$. The origin is at the left. Total recovery of radioactivity put on the gel was 95\%. The lower panel shows the migration of the ${ }^{3} \mathrm{H}-\mathrm{SV} 40 \mathrm{DNA}$ digestion products, designated $A$ through $K$ using the notation of Danna and Nathans (4). The upper panel shows the relationship between electrophoretic mobility and the percent of total (recovered) radioactivity which is present in each gel peak $(O)$, plotted on a logarithmic scale. The observed counts $(\Delta)$, in the third and fourth peaks from the origin, are divided by 2 .

100. After the second undiluted passage (Fig. $2 \mathrm{C}$ ), when $30 \%$ of the DNA molecules hybridize with BS-C-1 DNA, additional changes are seen. The small peak centered at slice 100 has increased in amount, and the area that originally contained fragments $\mathrm{C}$ through $\mathrm{K}$ is markedly altered. By the third passage (Fig. 2D), when at least $66 \%$ of the molecules hybridize to BS-C-1 DNA (Table 1), the cleavage pattern is radically different from that of the plaque-purified virus; the relative amounts of fragments $\mathrm{A}$ and $\mathrm{B}$ are each reduced by about $80 \%$, and additional new peaks are apparent in the gel. The accumulation of substituted viral DNA molecules during serial passage is directly correlated with at least one specific change in the cleavage pattern. As shown in Fig. 3, the relative amount (\% of total gel radioactivity) of the small peak centered at gel slice number 100 is directly proportional to the percentage of substituted viral DNA molecules present in the population prior to digestion with the endonuclease. We will show later that this small cleavage product (called peak 8 DNA) consists exclusively of BS-C-1 cell DNA sequences.
The gel positions of several of the cleavage products seen in Fig. 2D overlap with those seen with plaque-purified virus DNA (Fig. 2A). Therefore, to distinguish more precisely the digestion products characteristic of the SV40 DNA produced by serially passaged virus, the double-labeling experiment described in Fig. 4 was performed. The ${ }^{3} \mathrm{H}$-labeled component I SV40 DNA from cells infected with serially passaged virus (CVB, passage 3 ) and the ${ }^{32} \mathrm{P}$ labeled component I SV40 DNA from cells infected with plaque-purified CVB virus were mixed and digested with $H$. influenzae enzyme. The digestion products were analyzed by polyacrylamide gel electrophoresis (Fig. 4). The peaks of ${ }^{32} \mathrm{P}$ derived from the plaque-purified virus DNA are lettered A through $\mathrm{K}$, as in Fig. 1 and 2A; the peaks of ${ }^{3} \mathrm{H}$ derived from the serially passaged virus DNA, which appear to differ from the ${ }^{32} \mathrm{P}$ peaks in mobility, are denoted by the numbers 1 to 8 and by the letter $\mathrm{X}$. Several of the ${ }^{3} \mathrm{H}$ peaks (numbers, 1, 2, 4, 5, and 8) are clearly distinguishable from the ${ }^{32} \mathrm{P}$ peaks. However, other ${ }^{3} \mathrm{H}$ peaks $(\mathrm{X}, 3,6,7)$ overlap considerably with the positions of the 


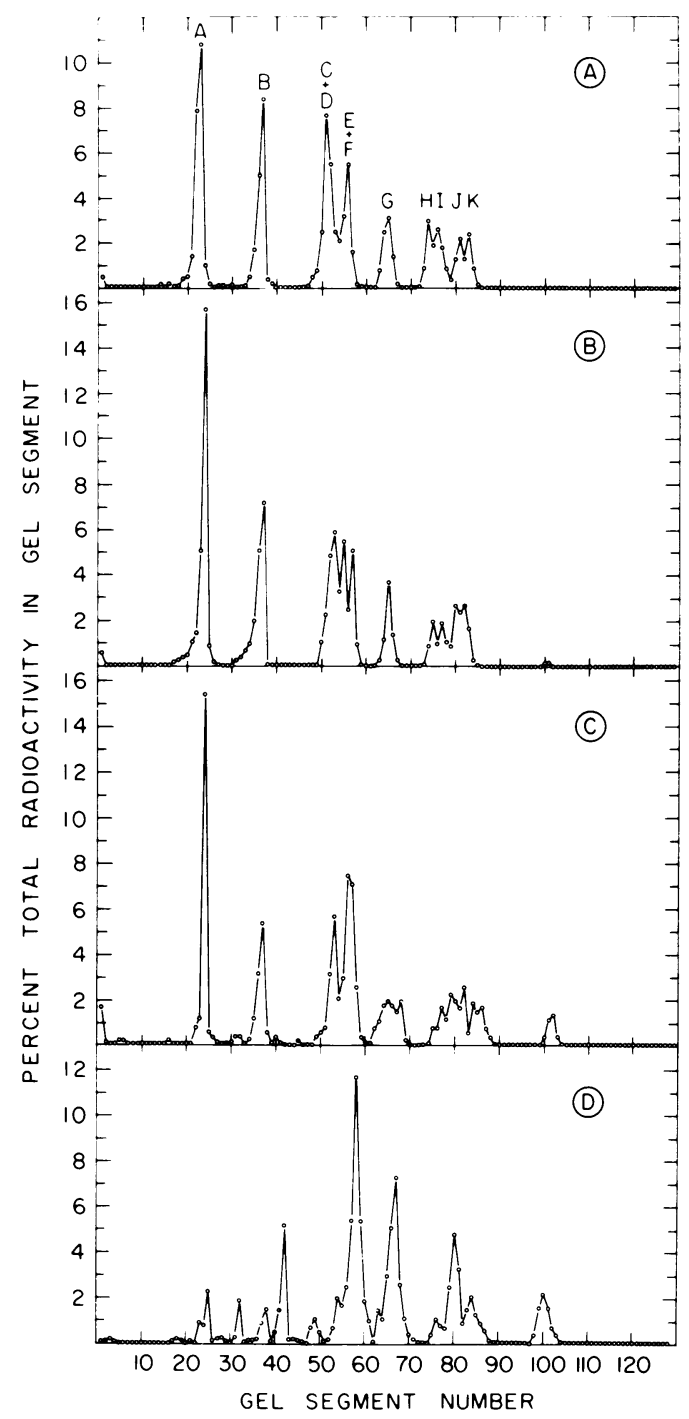

Fig. 2. Gel electrophoresis of plaque-purified and serially passaged SV40 DNAs after digestion with $H$. influenzae restriction endonuclease. ${ }^{3} \mathrm{H}-\mathrm{SV} 40 \mathrm{DNA} I$ was isolated and purified from $B S-C-1$ cells infected with: plaque-purified $C V B$ virus $(A) ; C V B$, passage 1 virus $(B)$; $C V B$, passage 2 virus $(C)$; and $C V B$, passage 3 virus $(D)$. See Table 1 for details of these virus preparations. The purified ${ }^{3} \mathrm{H}-\mathrm{SV} 40 \mathrm{DNA}$ from each infection was digested with endonuclease $(0.11 \mathrm{U}$ of enzyme per $\mathrm{ml}, 8 \mathrm{\mu g}$ of DNA per $\mathrm{ml}$ ), and the reaction products were either applied directly to the gels $(A, B, C)$ or first extracted with phenol prior to electrophoresis $(D)$. Electrophoresis was for $9 \mathrm{H}$. The recoveries of the input radioactivities $(100,000$ counts $/$ min in $A-C ; 180,000$ counts $/$ min in $D$ ) were $92 \%$ in $A$ and $B, 89 \%$ in $C$, and $79 \%$ in $D$.

cleavage products from plaque-purified DNA $\left({ }^{32} \mathrm{P}\right)$. To help resolve these overlap areas, the data in Fig. 4A are replotted as the ratio of percent of total ${ }^{3} \mathrm{H}$ to percent of total ${ }^{32} \mathrm{P}$ for each gel slice (Fig. 4B). This plot distinguishes those ${ }^{3} \mathrm{H}$ peaks (ratios greater than 1) whose mobilities differ from those of the ${ }^{32} \mathrm{P}$ fragments from plaque-purified virus DNA. Peaks X, 3, 6, and 7 (as well as $1,2,4,5$, and 8 ) clearly differ in mobility from the overlapping ${ }^{32} \mathrm{P}$ peaks and therefore contain new fragments characteristic of the serially passaged virus DNA. Thus, most of the radioactive material derived from the digestion of serially passaged virus DNA is present in 9 new sets of fragments; only a small proportion of the radioactive cleavage products migrates to positions characteristic of the products from plaque-purified virus DNA.

Cell DNA sequences in the cleavage products of serially passaged SV40 DNA I molecules. In the previous section, we showed that the $H$. influenzae restriction endonuclease cleaves substituted SV40 DNA into a series of fragments, most of which differ in electrophoretic mobility from those produced by the action of the same enzyme on plaque-purified virus DNA. The objective of the following experiments was to determine which of the fragments derived from substituted virus DNA contain the cellular DNA sequences. ${ }^{3} \mathrm{H}$-labeled

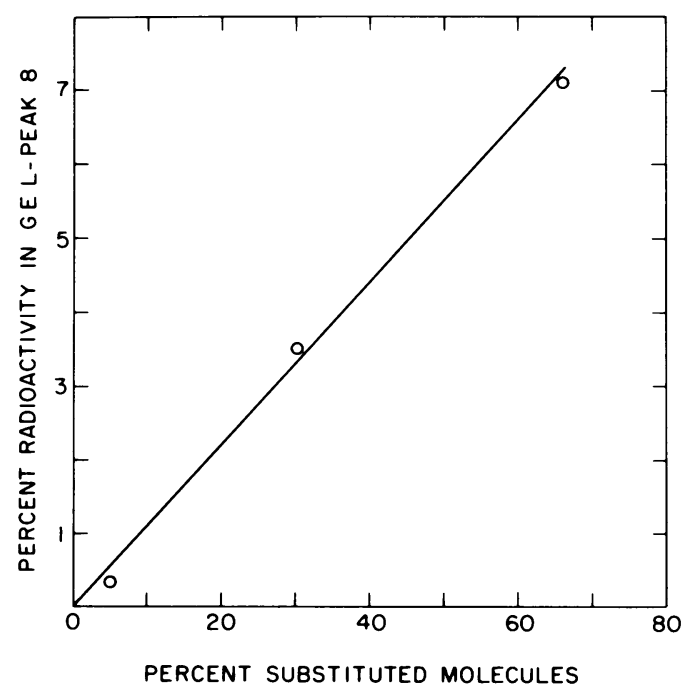

Fig. 3. Relationship between the proportion of substituted DNA molecules in serially passaged SV4O and the relative amount of peak 8 . The data for the percent substituted SV40 DNA molecules produced at different passage levels are taken from Table 1 (from the hybridization index: $(B S-C-1 / S V 40) \times 100)$. The data for the percent radioactivity in peak 8 is taken from Fig. 2 (panels $A-D$ ) and refers to the percentage of total gel radioactivity which is present in the peak centered at gel-slice number 100 (this peak is subsequently designated as peak 8; see Fig. 4). 


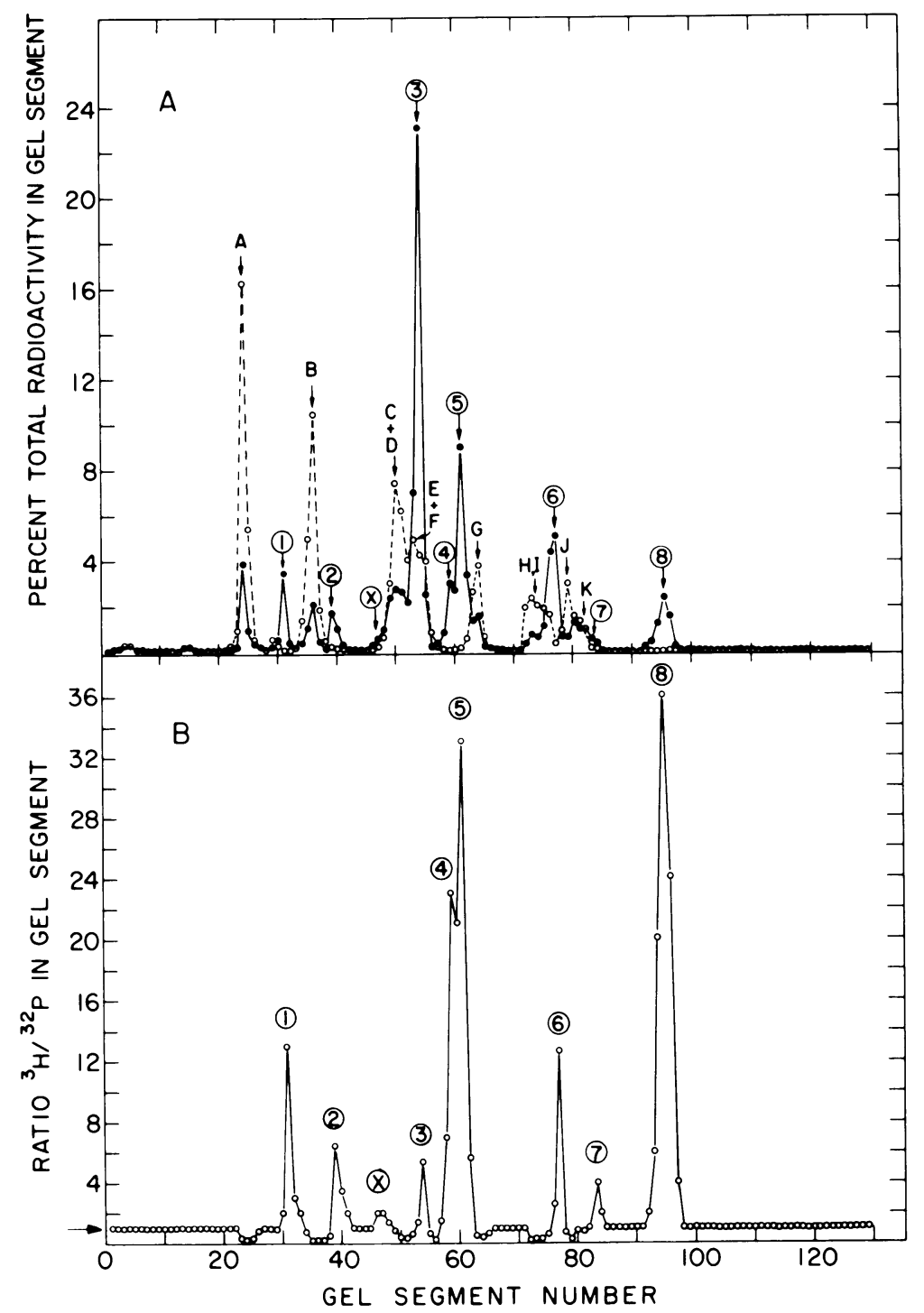

FIG. 4. Gel electrophoresis of a mixture of plaque-purified ${ }^{32} \mathrm{P}-\mathrm{SV} 40 \mathrm{DNA}$ and serially passaged ${ }^{3} \mathrm{H}-\mathrm{SV} 40$ $D N A$ after digestion of the mixture with $H$. influenzae restriction endonuclease. The plaque-purified ${ }^{32} P-S V 40$ DNA I and serially passaged ${ }^{3} \mathrm{H}-S V 40$ DNA I were isolated and purified from cells infected, respectively, with $C V B$ plaque-purified virus and CVB passage 3 virus (Table 1). The specific radioactivities were $1.5 \times 10^{5}$ counts per min per $\mu \mathrm{g}$ for ${ }^{3} \mathrm{H}$-DNA and $2.9 \times 10^{5}$ counts per min per $\mu \mathrm{g}$ for ${ }^{32} \mathrm{P}-\mathrm{DNA}$. The two preparations were mixed to give a ratio of $13 \mu \mathrm{g}$ of ${ }^{3} \mathrm{H}-\mathrm{DNA}$ per $\mu \mathrm{g}$ of ${ }^{32} \mathrm{P}-\mathrm{DNA}$, digested with $\mathrm{H}$. influenzae restriction enzyme at a concentration of $12 \mu \mathrm{g}$ of total DNA per $\mathrm{ml}$ and $0.11 \mathrm{U}$ of enzyme per $\mathrm{ml}$, and the digestion products were centrifuged on a neutral sucrose gradient. All of the digestion products sedimented in the 7 to $9 S$ region of the gradient. The digested material recovered from the sucrose gradient was then subjected to electrophoresis for 9 h. A, Percentage of total ${ }^{32} \mathrm{P}$ counts (- - - O- - ) and ${ }^{3} \mathrm{H}$ counts (-O-) in each gel segment (the recoveries were $84 \%$ and $96 \%$, respectively, of the total amounts of ${ }^{3} \mathrm{H}$ and ${ }^{32} \mathrm{P}$ put on the gel). The peaks of ${ }^{32} \mathrm{P}$ from the digestion of plaque-purified DNA are designated $A$ through $K$, as before; the ${ }^{3} H$ peaks (products from digestion of serially passaged DNA), whose positions in the gel differ from those of the ${ }^{32} P$ peaks, are designated with encircled numbers or the letter $X$. B, Ratio of percentage of ${ }^{3} \mathrm{H}$ counts to percentage ${ }^{32} P$ counts in each gel segment. The arrow on the vertical axis denotes a ratio of 1 .

component I SV40 DNA molecules were isolated from BS-C-1 cells infected with third-passage CVB virus (Table 1 , line 4) and digested with the endonuclease. The digest was fractionated on a polyacrylamide gel, and the ${ }^{3} \mathrm{H}$ fragments were eluted from the appropriate gel slices and tested for hybridization to filters containing either DNA from plaque-purified virus or DNA 
from BS-C-1 cells. The data in the first four columns of Table 2 are derived from analytical experiments with equivalent digests.

The size of the fragments in a given peak is estimated from the mobility in the gel by using the gel profile of the double-label experiment in Fig. 4 as a reference and assuming that peak $\mathrm{A}$, the largest fragment typical of plaque-purified virus, has a molecular weight of 700,000 (4). Taking the molecular weight of intact SV40 DNA component I to be $3 \times 10^{6}(3)$, the percentage of total radioactivity expected for a fragment of a given size can be calculated. By comparison of the expected percentage with the observed percentage, the number of fragments in each peak per cleaved molecule can be estimated. Table 2 indicates that the average number of fragments in the peaks numbered 1 , 2 , and $\mathrm{X}$ is less than 1 per molecule of SV40 DNA. In each of the other peaks characteristic of the serially passaged virus, that is, peaks number 3 through 8 , there are between three and four fragments per molecule of virus DNA.
Considering now the hybridization data obtained with the isolated fragments (Table 2, columns $5-8$ ), it is evident that the sequences capable of hybridizing with cell DNA, under the conditons used, are confined to two of the gel peaks, namely, peaks $X$ and 8 . Peak 8 DNA consists almost exclusively of BS-C-1 cell DNA sequences since the level of hybridization to plaque-purified SV40 DNA is extremely low ( $2 \%$ of the input was bound) whereas that to BS-C-1 cell DNA is very high (89\% of the input was bound). The high efficiency with which peak 8 fragments hybridize to BS-C-1 DNA indicates that some or all of the cell DNA sequences in this class of fragments must be of the reiterated type. The DNA fragments from peak X hybridize almost equally well with plaque-purified SV40 DNA and cellular DNA. At least some of the fragment(s) in peak $X$ contain covalently linked cell and viral sequences since material recovered from the hybrid complexes with either BS-C-1 cell DNA or viral DNA re-hybridizes back to the opposite DNA (data not

TABLE 2. Stoichiometry and hybridization data for fragments obtained by $H$. influenzae endonuclease digestion of serially passaged SV40 DNA ${ }^{a}$

\begin{tabular}{|c|c|c|c|c|c|c|c|}
\hline \multirow{2}{*}{$\begin{array}{c}\text { Gel } \\
\text { peak }\end{array}$} & \multirow{2}{*}{$\begin{array}{l}\text { \% of total } \\
\text { counts } / \mathrm{min} \\
\text { in } \text { gel }^{\circ}\end{array}$} & \multirow{2}{*}{$\begin{array}{l}\text { Approximate size from } \\
\text { electrophoretic mobility } \\
\text { (daltons) })^{c}\end{array}$} & \multirow{2}{*}{$\begin{array}{l}\text { Avg no. of } \\
\text { fragments per } \\
\text { molecule }{ }^{d}\end{array}$} & \multirow{2}{*}{$\begin{array}{l}\text { Counts } / \mathrm{min} \\
\text { input to } \\
\text { hybridization }\end{array}$} & \multicolumn{3}{|c|}{$\%$ input hybridized to: } \\
\hline & & & & & $\begin{array}{l}\text { SV40 } \\
\text { DNA }^{e}\end{array}$ & $\begin{array}{l}\text { BS-C-1 } \\
\text { DNA }\end{array}$ & Blank \\
\hline $\begin{array}{c}1 \\
2 \\
\mathrm{X} \\
3 \\
4+5 \\
6 \\
7 \\
8\end{array}$ & $\begin{array}{r}3.8 \\
4.1 \\
2.7 \\
33.0 \\
21.0 \\
12.9 \\
6.1 \\
7.1\end{array}$ & $\begin{array}{r}570,000 \\
430,000 \\
320,000 \\
260,000 \\
210,000 \\
115,000 \\
93,000 \\
60,000\end{array}$ & $\begin{array}{l}0.20 \\
0.28 \\
0.25 \\
3.8 \\
3.0 \\
3.4 \\
2.0 \\
3.5\end{array}$ & $\begin{array}{r}249 \\
354 \\
2,108 \\
12,301 \\
10,950 \\
11,562 \\
5,985 \\
5,734\end{array}$ & $\begin{array}{r}61 \\
102 \\
48 \\
47 \\
55 \\
13 \\
40 \\
2\end{array}$ & $\begin{array}{c}2 \\
5 \\
41 \\
1 \\
1 \\
0.5 \\
2 \\
89\end{array}$ & $\begin{array}{l}0.8 \\
0.3 \\
0 \\
0.1 \\
0 \\
0 \\
0 \\
0\end{array}$ \\
\hline \multicolumn{4}{|c|}{$\begin{array}{l}\text { Total digest before gel fractionation } \\
\text { Total digest eluted from SV } 40 \text { filter } \\
\text { Total digest eluted from BS-C-1 filter }\end{array}$} & $\begin{array}{r}3,464 \\
829 \\
241\end{array}$ & $\begin{array}{l}81 \\
76 \\
22\end{array}$ & $\begin{array}{r}12 \\
3 \\
71\end{array}$ & $\begin{array}{l}0 \\
0 \\
0\end{array}$ \\
\hline
\end{tabular}

${ }^{a}$ A 4- $\mu$ g amount of purified ${ }^{3} \mathrm{H}-\mathrm{SV} 40$ DNA component $\mathrm{I}$, from cells infected with CVB, passage 3 virus (see Table 1) were digested with $H$. influenzae endonuclease. The concentrations of DNA and enzyme were $33 \mu \mathrm{g} / \mathrm{ml}$ and $0.44 \mathrm{U} / \mathrm{ml}$, respectively, and the digest was subjected to electrophoresis for $9 \mathrm{~h}$ after phenol extraction. DNA was eluted from the gel slices, pooled corresponding to peaks 1 to 8 and $\mathrm{X}$ in Fig. 4, and tested for hybridization, as described in Materials and Methods.

o The results in this column were obtained from analytical gel electrophoresis of identical ${ }^{3} \mathrm{H}-\mathrm{SV} 40$ DNA digests (same ${ }^{3} \mathrm{H}-\mathrm{SV} 40$ DNA preparation, same DNA-to-enzyme ratio) as that described in footnote $a$ above. The gel slices were counted (the total recovery of radioactivity applied to the gels was 79 to $90 \%$ ) and the percent of total activity in each peak was calculated. The values shown are the averages from 4 separate analytical gel electrophoresis runs (the stated average values are $\pm 2 \%$ )

$c$ The approximate size of the fragments in each peak was calculated with reference to the double-label experiment of Fig. 4, assuming that peak A of plaque-purified virus has a molecular weight of $700,000(4)$ and that molecular weight is proportional to electrophoretic mobility. It should be noted that the material on the gel is double-stranded DNA.

${ }^{d}$ The average number of fragments derived from each cleaved molecule was calculated from the percent of total counts in the peak, and the percent of the total SV40 DNA component I expected in a fragment of a given size (see text). The molecular weight of component I was taken to be $3 \times 10^{6}(3)$.

- Plaque-purified SV40 DNA I. 
shown). However, peak $\mathrm{X}$ fragments do not appear to be characteristic of the majority of substituted SV40 DNA molecules since the stoichiometry observed for this class of DNA fragments indicates that they are derived from only a minor fraction of the population (Table 2 , column 4). Hybridization experiments with the total, unfractionated digest confirm that digestion with $H$. influenzae endonuclease effectively separates the bulk of the SV40 sequences from the bulk of the reiterated host sequences in the substituted molecules (last 3 lines of Table 2). Of the $81 \%$ of the total digest fragments that hybridizes to filters containing plaque-purified SV40 DNA, only 3\% hybridizes back to cell DNA after elution from the SV40 filters. Similarly, of the $12 \%$ of the total digest that hybridizes to BS-C-1 DNA, only $22 \%$ hybridizes back to SV40 DNA after elution from the BS-C-1 filters. Hence, over three-quarters of the fragments which hybridize to host DNA contain no SV40 sequences. Only about $3 \%(22 \%$ of $12 \%)$ of the material in the digest of substituted molecules consists of chains containing covalently linked viral and reiterated cellular DNA sequences. This minor fraction is consistent with the stoichiometry observed for peak X, namely, $2.7 \%$ of the total gel radioactivity.

It will be noted from Table 2 that the fragments in peak 6 show a surprisingly low level of hybridization to plaque-purified SV40 DNA and do not hybridize with BS-C-1 DNA. These fragments were therefore tested for their ability to hybridize with filters containing the same serially passaged virus DNA from which they were originally obtained. The results (Table 3 ) show that peak 6 fragments hybridize much more efficiently with the serially passaged virus DNA than with plaque-purified DNA. Doubling the amount of plaque-purified SV40 DNA on the filter did not increase the percentage of peak 6 DNA bound (data not shown). Hence, the increased efficiency of hybridization to serially passaged DNA is unlikely to be due to a duplication of SV40 sequences. The most reasonable interpretation of these observations is that most of the fragments from peak 6 consist of cellular DNA sequences that are too unique (with respect to the cellular genome) to register in the DNA-DNA hybridization test which uses total cell DNA immobilized on filters. The minor fraction of peak 6 fragments which hybridizes to plaque-purified virus DNA $(13 \%-16 \%$, Tables 2 and 3$)$ could well be due to contamination with peak I DNA (Fig. 4) which derives from the small amount of plaque-forming virus DNA still present in the serially passaged preparation. The data in Table 3 also confirm that the fragments in peak 8 , which consist exclusively of cell DNA sequences, hybridize, as expected, to serially passaged SV40 DNA and not to plaque-purified virus DNA.

An estimate of the proportion of cell DNA sequences in the average substituted SV40 DNA molecule. The proportion of cell DNA sequences per substituted SV40 DNA molecule can be estimated from the data in Tables 1-3 provided the following assumption is made. We assume that there is only one major class of substituted molecules in the population and that each of these molecules gives rise to both peak 8 and peak 6 DNA. This major class of molecules comprises $66 \%$ of the population (Table 1). The remaining fraction of the population consists of nonsubstituted, plaque-forming DNA (the specific infectivity of this serially passaged DNA is about $15 \%$ that of the plaquepurified DNA [6]) and a minor class of substituted molecules which gives rise to the DNA of gel peaks 1, 2, and X. Molecules containing deletions, but no substitutions, may also be present. The following estimate refers only to the major class of substituted molecules.

The DNA of peak 8 , which contains only host sequences, comprises $7.1 \%$ of the total DNA recovered from the gel (Table 2) (the proportion of gel peak 8 in the digest of substituted molecules labeled with ${ }^{32} \mathrm{P}$ is the same as in the digest of ${ }^{3} \mathrm{H}-\mathrm{TdR}$-labeled molecules, indicating that possible variations in average base composition do not seriously affect the estimated proportion of peak 8 DNA). Hence, $10.7 \%$ $[(7.1 / 66) \times 100]$ of the sequences in the substituted viral genome are cell DNA sequences either wholly or partly of the reiterated type. The data do not exclude the possibility that peak 8 DNA contains unique cell DNA sequences covalently linked to reiterated cell

\begin{tabular}{c|c|c|c|c|c}
\multicolumn{5}{c}{ TABLE 3. Hybridization of peak 6 fragments to } \\
serially passaged SV40 DNA
\end{tabular}

${ }^{a}$ This is the same material described in Table 2.

${ }^{b} \mathrm{SV} 40$ DNA I $(10 \mu \mathrm{g} /$ filter $)$ from a plaque-purified (not serially passaged) stock.

${ }^{c}$ SV40 DNA I (10 $\mu \mathrm{g} /$ filter) isolated from BS-C-1 cells (unlabeled) infected with CVB, passage 3 virus. Hence, this SV40 DNA is equivalent to the ${ }^{3} \mathrm{H}-\mathrm{SV} 40$ DNA from which peak 6 and peak 8 fragments were cleaved. 
DNA sequences. Peak 6 DNA comprises $12.9 \%$ of the total radioactivity recovered from the gel; however, an average $14.5 \%$ of this DNA consists of viral sequences (13\% in Table 2 and $16 \%$ in Table 3$)$. Thus, approximately $11 \%(85.5 \%$ of $12.9 \%$ ) of the total sequences in the population, or $16.7 \%[(11 / 66) \times 100]$ of the sequences in the average, substituted SV40 DNA molecule are assumed to be unique host sequences. On the basis of peak 8 and peak 6 DNA alone, we therefore estimate that $27.4 \%$ of the sequences in the average substituted genome (or 1,370 out of 5,000 base pairs) are host DNA sequences, the majority being of the unique type. The proportion of unique host DNA sequences per substituted genome must be regarded as a minimum estimate since several of the other peaks described in Table 2 may also contain host sequences of this type.

\section{DISCUSSION}

The presence of reiterated or repetitious $(2,8)$ host sequences in some preparations of closedcircular SV40 DNA was predicted from the high eficiency with which substituted viral DNA hybridizes with total cell DNA immobilized on nitrocellulose membrane filters $(1,6,7)$. This prediction is fully confirmed and extended by the hybridization analysis of the specific fragments produced by digesting substituted SV40 DNA with the $H$. influenzae restriction endonuclease. Reiterated cell DNA sequences were detected in two of the nine classes of fragments distinguishable by gel electrophoresis. One of these classes, peak X, does not appear to arise from every substituted molecule. The second class of fragments (peak 8) hybridizes with extremely high efficiency to cell DNA and is virtually free of SV40 sequences. The stoichiometric data in Table 2 is consistent with our assumption that peak 8 fragments are derived from the majority of substituted molecules; furthermore, the relative amount of this class of fragments is closely correlated with the proportion of intact SV40 DNA strands which hybridize to cell DNA prior to cleavage (Fig. 3). The hybridization analysis of the $H$. influenzae endonuclease products has also suggested the presence of nonreiterated, or unique, host sequences in the substituted SV40 genome. The fragments derived from peak 6 show no detectable hybridization with filters containing cell DNA and hybridize poorly with filters containing plaque-purified virus DNA. On the other hand, they hybridize with very high efficiency to filters containing the same serially passaged virus DNA from which they were originally obtained. We interpret this unusual hybridiza- tion pattern as being indicative of the presence of cell DNA sequences too unique to register in the direct hybridization reaction with cell DNA immobilized on the filter. The high level of hybridization to serially passaged SV40 DNA is then expected since the replication of substituted virus DNA molecules (6) will convert sequences which were originally unique with respect to the genome of the host cells into sequences which are now reiterated with respect to the population of substituted viral DNA molecules.

Assuming that the serially passaged population of SV40 DNA molecules studied contains only one major class of substituted molecules, we estimate that $27.4 \%$ of the sequences in this class of substituted viral genomes are host sequences $(10.7 \%$ from the data on peak 8 DNA plus $16.7 \%$ from the data on peak 6 DNA). The majority of these sequences are probably of the unique type (peak 6 DNA). If DNA from several of the other peaks described in Table 2 contain unique host sequences, then our approximation of the total host substitution will be an underestimate. It should also be stressed that the total extent of the host substitution may be different in other populations of substituted SV40 DNA. We do not know if the host sequences in the substituted viral genomes studied here are contiguous or not. In this connection, it is interesting to note that, in electron microscopy studies on renatured SV40 DNA, derived from non-plaque-purified virus passaged at high multiplicity, Tai et al. (11) observed heteroduplex molecules with a continuous "substitution loop," on the average $20 \%$ the length of SV40 DNA. It is likely that the substitution loop observed by these authors consists of contiguous host DNA sequences.

The accumulation of substituted viral DNA molecules during serial, undiluted passage is accompanied by a radical change in the way the molecules are cleaved by the $H$. influenzae endonuclease (Fig. 2 and 4A). By the third undiluted serial passage of CVB virus (when at least $66 \%$ of the progeny virus DNA molecules hybridize to host cell DNA), most of the gel peaks characteristic of plaque-purified virus DNA have decreased markedly and have been replaced by new sets of fragments. Such alterations could result from the deletion of SV40 sequences containing endonuclease recognition sites, from the deletion of SV40 sequences between recognition sites, and from the presence of host DNA sequences which themselves provide recognition sites for the enzyme (in unpublished experiments we have found that BS-C-1 cell DNA itself is a good substrate for the endonuclease). 
It should be noted that the present studies on the substituted virus DNA fragments produced by the $H$. influenzae restriction endonuclease supply additional evidence for the replication of such molecules in infected cells. Thus, after labeling with ${ }^{3} \mathrm{H}-\mathrm{TdR}$, both viral and cellular DNA sequences are radioactive. The finding that the relative amount of peak $8 \mathrm{DNA}$ is linearly related to the proportion of substituted molecules in the serially passaged DNA prior to cleavage (Fig. 2) indicates that the average proportion of reiterated cell DNA per molecule does not change appreciably during the first three serial passages. This result is consistent with our suggestion (6) that an important effect of the serial, undiluted (that is, high multiplicity) passage of the virus is to provide conditions for the preferential replication of a small number of substituted molecules that arose during earlier passages. Finally, it should be re-emphasized that the findings reported in this paper concern the nature of substituted SV40 DNA produced during a particular set of serial passages. We have demonstrated that independent series of passages yield different types of defective virus DNA (6). It remains to be seen, therefore, if the substituted virus DNA produced during independent sets of serial passages is similar or not. It will also be important to determine if the deleted SV40 sequences are the same in different populations of substituted virus DNA.

\section{ACKNOWLEDGMENTS}

We wish to thank B. Danovitch for his cheerful and expert technical assistance. One of us (M.F.S.) is especially indebted to the National Institute of Arthritis, Metabolism, and Digestive Diseases, National Institutes of Health, for the opportunity to spend a year at the Weizmann Institute. This work was partly supported by grant DRG-1060-B from the Damon Runyon Memorial Fund for Cancer Research, and by Public Health Service Research Grant CA-14530 from the National Cancer Institute.

\section{LITERATURE CITEC}

1. Aloni, Y., E. Winocour, L. Sachs, and J. Torten. 1969. Hybridization between SV40 DNA and cellular DNAs. J. Mol. Biol. 44:333-345.

2. Britten, R. J., and D. E. Kohne. 1968. Repeated sequences in DNA. Science 161:529-540.

3. Crawford, L. V., and P. H. Black. 1964. The nucleic acid of simian virus 40. Virology 24:388-392.

4. Danna, K. J., and D. Nathans. 1971. Specific cleavage of simian virus 40 DNA by restriction endonuclease of $H$. influenzae. Proc. Nat. Acad. Sci. U.S.A. 68:2913-2917.

5. Kelly, T. J., and H. O. Smith. 1970. A restriction enzyme from Hemophilus influenzae. II. Base sequence of the recognition. J. Mol. Biol. 51:393-409.

6. Lavi, S., S. Rozenblatt, M. F. Singer, and E. Winocour. Acquisition of sequences homologous to host DNA by closed circular simian virus 40 DNA. II. Further studies on the serial passage of virus clones. J. Virol. 12:492-500.

7. Lavi, S., and E. Winocour. 1972. Acquisition of sequences homologous to host deoxyribonucleic acid by closed circular simian virus 40 deoxyribonucleic acid. J. Virology 9:309-316.

8. Melli, M., and J. O. Bishop. 1969. Hybridization between rat liver DNA and complementary RNA. J. Mol. Biol. 40:117-136.

9. Nathans, D., and K. J. Danna. 1972. Studies of SV40 DNA. III. Differences in DNA from various strains of SV40. J. Mol. Biol. 64:515-518.

10. Smith, H. O., and K. W. Wilcox. 1970. A restriction enzyme from Hemophilus influenzae. I. Purification and general properties. J. Mol. Biol. 51:379-392.

11. Tai, H. T., C. A. Smith, P. A. Sharp, and J. Vinograd. 1972. Sequence heterogeneity in closed simian virus 40 deoxyribonucleic acid. J. Virol. 9:317-325.

12. Vinograd, J., J. Lebowitz, R. Radloff, R. Watson, and P. Laipis. 1965. The twisted circular form of polyoma viral DNA. Proc. Nat. Acad. Sci. U.S.A. 53:1104-1111.

13. Young, R. W., and H. W. Fulhorst. 1965. Recovery of $\mathrm{S}^{3}$ radioactivity from protein-bearing polyacrylamide gel. Anal. Biochem. 11:389-391. 